\title{
O Orçamento Participativo do Rio de Janeiro e as Políticas de Planejamento Urbano Estratégico
}

\author{
Isabel Cristina da Costa Cardoso*
}

\begin{abstract}
Resumo: A cidade do Rio de Janeiro tem se destacado como palco das políticas de empreendedorismo urbano sob influência de agências multilaterais como o Banco Mundial (BIRD). Para aprofundar a compreensão do significado deste "ajuste", o artigo analisa fontes documentais do Segundo Plano Estratégico da Cidade do Rio de Janeiro e das estratégias do BIRD para a cidade. A partir deste procedimento metodológico, problematiza a subordinação do orçamento participativo à gestão empreendedora do planejamento estratégico. $\mathrm{O}$ objetivo é realçar a forma como as políticas de empreendedorismo urbano operam a partir da anulação da política.
\end{abstract}

Palavras-chave: Empreendedorismo urbano; orçamento participativo; planejamento urbano; Segundo plano estratégico do Rio de Janeiro.

\begin{abstract}
Rio de Janeiro city has been the stage for politics of urban enterprising under influence of multilateral agencies as the World Bank (BIRD). This article intents to deepen the understanding of this "adjustment", analyzing documentary sources of Second Strategical Plan of Rio de Janeiro City and the strategies of BIRD for the city. Questioning the subordination of participative budget to the enterprising management of strategical planning, the paper aims to show how the politics of urban enterprising operates annihilating politics.
\end{abstract}

Keywords: Urban enterprising; participative budget; urban planning; Second strategical plan of Rio de Janeiro.

\section{Introdução}

O texto tem como objetivo analisar a subordinação do orçamento participativo da cidade do Rio de Janeiro à gestão empreendedora do planejamento estratégico da cidade e demonstrar a forma como as políticas de empreendedorismo urbano operam a partir da desnecessidade da política, ao mesmo tempo que a ritualiza em um conjunto de procedimentos, técnicas, documentos, cifras, indicadores

\footnotetext{
* Assistente Social. Mestre em Serviço Social pela Universidade Federal do Rio de Janeiro. Doutora em Sociologia pela Universidade de São Paulo. Professora adjunta do Departamento de FTPSS e Pesquisadora do Programa de Estudos de Trabalho e Política da Faculdade de Serviço Social da Universidade do Estado do Rio de Janeiro. Endereço postal: Rua São Francisco Xavier, 524, sala 8023, bloco E, Maracanã, Rio de Janeiro, CEP: 20550.900. Endereço eletrônico: icostac@superig.com.br.
} 
e propostas que possui a capacidade de se apropriar de vários elementos institucionais da democracia participativa para então esvaziá-la inteiramente de seu sentido.

Parta tanto, o texto parte do conceito de ajuste urbano formulado por Arantes (2004) para analisar o processo de construção do Segundo Plano Estratégico da cidade do Rio de Janeiro (II PECRJ), encaminhado na transição ao novo século XXI. Um conjunto de práticas dá materialidade a esta cena urbana do planejamento es-tratégico e coloca em evidência o que Milton Santos já ensinara: "que no espaço geográfico se as temporalidades não são as mesmas, para os diversos agentes sociais, elas todavia se dão de modo simultâneo (2004, p. 159). Nesse sentido, o texto discute a ação do Banco Mundial (BIRD) na construção de uma agenda de boa governança para as cidades dos países subdesenvolvidos e, em especial, analisa documentos institucionais do banco que materializam a agenda do BIRD para a cidade do Rio de Janeiro. A presença significativa das redes globais, por meio das quais agências multilaterais, como o referido banco, interagem no território do Rio de Janeiro, transforma de maneira significativa as trajetórias urbanas da cidade a partir da transição dos anos 1990 aos anos 2000. O fenômeno de crescimento das práticas de empreendedorismo urbano (HARVEY, 2005), como referência do planejamento urbano municipal, e a consequente subordinação da política à gestão empresarial/empreendedora do planejamento estratégico constitui a principal expressão desta transformação analisada pelo texto. É nesta chave interpretativa que o orçamento participativo da cidade do Rio de Janeiro é recortado e elevado ao centro das discussões.

Frente a esse desenho metodológico para problematização das questões aqui investigadas, o texto inicia pela contextualização histórica, na cidade do Rio de Janeiro, do discurso da "boa governança" formulado pelo BIRD. Para tanto, situa este marco inaugural a partir da gestão do ex-prefeito Cesar Maia, ${ }^{1}$ desde o momento inicial de seu primeiro mandato, mais precisamente a partir de 1993, por meio da introdução da política de planejamento estratégico da cidade, orientada pelos fundamentos do empreendedorismo urbano (VAINER, 2000; COMPANS, 2005, HARVEY, 2005). No segundo segmento do texto, apresentam-se os fundamentos e as propostas da agenda de boa governança do BIRD para a cidade do Rio de Janeiro e discute-se a articulação entre tal agenda e o aprofundamento das políticas de planejamento estratégico da cidade, por meio da elaboração do Segundo Plano Estratégico da Cidade do Rio de Janeiro (II PECRJ). A terceira parte, dedica-se à análise do processo de subordinação da política do orçamento participativo de 2003-4 à dinâmica de elaboração do II PECRJ. O texto conclui que o conjunto dos elementos analisados produzem a anulação da política e o esvaziamento da experiência

\footnotetext{
${ }^{1}$ César Maia esteve à frente da Prefeitura do Rio de Janeiro desde 1993 até 2008. Apenas o mandato de 19972000 foi exercido por Luiz Paulo Conde, ex-secretário de urbanismo de César Maia e candidato lançado pelo então prefeito. Tal aliança, contudo, foi interrompida durante o processo eleitoral de 1999, quando Conde lançou sua candidatura à reeleição e rompeu o pacto de apoio à candidatura de César Maia.
} 
democrática por meio da sua subordinação à lógica do planejamento estratégico e aos mecanismos de criação de um "consenso ordeiro" sobre os destinos da cidade.

\section{A ação do Banco Mundial}

\section{na Construção do Sentido de "Boa Governança" das Cidades}

A inserção da cidade do Rio de Janeiro na agenda das políticas de "boa governança", elaboradas e financiadas por agências multilaterais como BIRD, caminha lado a lado com a introdução das políticas de empreendedorismo urbano. Conforme conceituação de Harvey (2005), tais políticas caracterizam-se pela implementação de parcerias ou consórcios entre as esferas pública e privada para a implementação de políticas de desenvolvimento urbano, orientadas por critérios mercantis advindos da lógica empresarial. A adoção de tais políticas em escala mundial, persegue o objetivo de transformação e adaptação das cidades em cidades globais, a partir das demandas do processo de globalização econômica que se expressam centralmente, segundo Sassen (1998) e Castells (2002), pelo refluxo das atividades industriais clássicas e o crescimento do setor terciário avançado da economia capitalista. Para tanto, a gestão urbana das cidades pressupõe a utilização de mecanismos que potencializam a concorrência interurbana global e local entre cidades, como o planejamento estratégico e o marketing urbano, para atração e captação dos fluxos de investimento do capital no território das cidades.

São várias as inspirações teóricas destas políticas de empreendedorismo urbano, como a teoria da cidade-global de Sassen e a teoria da cidade do terciário de Castells e a conceituação da cidade como ator político de Castells e Borja (1996). Cabe destacar aqui, contudo, o que Logan e Molotoch (apud FERREIRA, 2007) conceituam como "teoria da máquina de crescimento". A partir desta referência, os autores demonstram as características e os resultados da dinâmica urbana de produção do espaço, notadamente do papel da dinâmica intraurbana, quando a correlação de forças entre os agentes urbanos e seus interesses está pautada pela subordinação da lógica do valor de uso da cidade sobre a lógica do valor de troca. Conforme a análise de Ferreira demonstra:

Segundo Logan e Molotoch, como a busca de valores de troca permeia a vida das cidades, ela acaba impondo-se sobre a dimensão do valor de uso. As chamadas "classes rentitas" se organizam em coalizões que envolvem os proprietários fundiários, os políticos locais, a mídia, as agências de serviços públicos, setores sindicais, instituições culturais como museus e universidades, equipes esportivas, comerciantes, enfim, todos aqueles que têm algo a ganhar com o "crescimento" da cidade. O poder político dessas coalizões torna as cidades verdadeiras "empresas devotadas ao crescimento da renda agregada através da intensificação do uso do solo urbano". É a "máquina de crescimento urbano", uma abordagem que se atém com muito mais ênfase às dinâmicas intraurbanas de produção da cidade (LOGAN e MOLOTOCH, apud FERREIRA, 2007, p. 152). 
Pode-se considerar o início dos anos 1990 marco inaugural de inserção da cidade do Rio de Janeiro nesta dinâmica das políticas de empreendedorismo urbano, quando do momento da elaboração do I PECRJ. ${ }^{2}$

No ano de 1993 foi firmado um acordo de cooperação entre a Associação Comercial do Rio de Janeiro (ACRJ), a Federação das Indústrias do Rio de Janeiro (FIRJAN) e a Prefeitura da cidade para dar início ao I PECRJ, posteriormente intitulado "Rio sempre Rio". Para tanto, foi formado um consórcio mantenedor, majoritariamente composto por empresas ou organizações privadas, que custeou a contratação da firma catalã "Tubsa - Tecnologies Urbanes de Barcelona S.A.". Tal empresa foi responsável pelo Plano Estratégico da cidade de Barcelona e pelo sucesso da fórmula - a partir daí multiplicada em escala global - de associação do planejamento urbano a um grande evento, de preferência inserido no calendário mundial de festividades e competições, ou a um produto cultural de forte valor agregado em torno de sua marca, como os museus internacionais, capaz de funcionar como estratégia de marketing e venda da imagem da cidade. No caso específico de Barcelona, a estratégia foi a realização dos Jogos Olímpicos de 1992.

Segundo os consultores mundiais do planejamento estratégico de cidades que vendem seus serviços pelo mundo, a condição de sucesso de tais políticas de empreendedorismo urbano é a transformação da cidade em "cidade empresa" e em "cidade mercadoria" (COMPANS, 2005; VAINER, 2000). A cidade empreendedora, ou "cidade-empresa", é aquela que adota alguma medida de empreendedorismo urbano visando à sua transformação em uma cidade competitiva e adaptada, ainda que de forma subalterna, às disputas por um lugar nos fluxos e processos das redes globais do capital.

O planejamento estratégico constitui o principal instrumento de adap-tação das formas institucionais locais aos objetivos da inserção competitiva, ao referenciar uma agenda de intervenções físicas e de modificações na estrutura legal e administrativa a tendências mercadológicas observadas na dinâmica da economia global. Atribuindo a relevância estratégica a determinadas ações e projetos, exclui a possibilidade de que outras, não-incluídas nesta agenda, sejam efetivadas ou mesmo reivindicadas. Por outro lado, o planejamento estratégico favorece a construção de alianças políticas com os segmentos médios e empresarias e o marketing público, ambos conferindo legitimidade às prioridades estabelecidas e à participação do setor privado na gestão dos negócios públicos. Desta forma, torna-se um veículo privilegiado para a adoça do empreendedorismo competitivo na gestão das cidades (COMPANS, 2005, p. 23).

\footnotetext{
${ }^{2}$ O I PECRJ se expressa num conjunto de sete estratégias: O carioca do século XXI; Rio acolhedor; Rio participativo; Rio integrado; Portas do Rio; Rio competitivo; Rio 2004, polo regional, nacional e internacional. A articulação entre as estratégias, seus objetivos, ações e projetos constitui o cerne do I PECRJ. A elaboração de um diagnóstico da cidade foi a atividade inicial e propulsora para a dinâmica de elaboração do I PECRJ. A metodologia, elaborada pelos consultores do I PECRJ, seguiu uma classificação polarizada em dois tipos de diagnóstico: positivo e negativo. Assim, para cada elemento considerado negativo da cidade, era necessário pensar, paralelamente, um elemento positivo que atuasse como potencializador da cidade e que fundamentaria o chamado "projeto de cidade" a ser materializado no I PECRJ. Foge aos objetivos do texto o aprofundamento sobre a experiência do I PECRJ. A este respeito, indica-se a leitura de Cardoso (2005), Compans (2005) e Vainer (2000).
} 
Da mesma forma, a gestão urbana de tal cidade deve se orientar pela formulação de uma política de "marketing urbano" por meio da qual a cidade se coloca na "vitrine" do mercado mundial de cidades (VAINER, 2000). É sob esta condição que a cidade assume a característica de cidade-mercadoria:

Talvez esta seja, hoje, uma das ideias mais populares entre os neoplanejadores urbanos: a cidade é uma mercadoria a ser vendida, num mercado extremamente competitivo em que outras cidades também estão à venda. Isto explicaria que o chamado marketing urbano se imponha cada vez mais como uma esfera específica e determinante do processo de planejamento e gestão das cidades. [...] A cidade, porém, reconhecerão mesmo seus mais convictos vendedores, é certamente a mais complexa de quantas mercadorias jamais existiram. Nestas condições, o que é que, afinal de contas, se vende quando se põe á venda uma cidade? A resposta não é fácil, pois, na verdade, ela depende de quem se tem em vista como comprador (VAINER, 2000, p. 78).

O discurso da gestão financeira eficiente e competitiva como a de uma empresa e a adoção de políticas de marketing urbano de promoção da imagem da cidade como um produto a ser consumido, foi uma marca forte da gestão do governo César Maia à frente da prefeitura da cidade do Rio de Janeiro. Mas é necessário ultrapassar este primeiro patamar de associação pessoal para articulá-lo às bases mais profundas de poder que pressionam as margens de autonomia e ação dos governos, tanto locais quanto nacionais, bases estas que podem ser encontradas em diferentes escalas do espaço por onde os processos de acumulação capitalista, as expressões materiais da divisão internacional do trabalho e a luta política pela hegemonia se processam. Interessa aqui reter a escala de atuação das redes transnacionais extensivas por meio das quais organismos como o BIRD atuam sobre os espaços locais das cidades. Um primeiro exemplo da arquitetura institucional destas redes pode ser buscado na atuação de agências internacionais de classificação da condição de "risco" dos diferentes territórios.

Além de motivo de "orgulho", a gestão eficiente é também "moeda de troca" para captação dos recursos financeiros no mercado mundial. A situação financeira do Rio de Janeiro porém, para se transformar em uma referência "sólida" para o capital mundial, precisa passar pelos processos de classificação das agências de qualificação de risco de crédito. Ou seja, além de buscar reduzir o chamado "custo Rio" é necessário reduzir o "risco Rio", sem o qual não se conquista uma posição no mercado mundial das cidades. Esta parece ser uma lição não apenas aprendida pela Prefeitura, como também valorizada:

A solidez financeira da cidade pode ser comprovada na avaliação da Moody's Investors Service, agência internacional de análise do risco de crédito, que este mês elevou a posição da cidade 
em relação à capacidade de contrair dívida em moeda estrangeira do nível B1 para B1 positivo, mesmo nível de avaliação do Brasil.

De acordo com as regras das agências internacionais de avaliação de risco de crédito, uma cidade ou um estado não pode ultrapassar a classificação conferida ao seu país.

Esta melhora no raking confirma a trajetória já delineada em setembro do ano passado, quando a agência elevou a nota do Município do nível B2 para o B1. A Moody's é uma das mais conceituadas agências de qualificação de risco de crédito do mundo e os seus relatórios avaliam a receita e o patrimônio, que servem como referência para as tentativas da Prefeitura de captar recursos de fontes nacionais e estrangeiras (PREFEITURA DA CIDADE DO RIO DE JANEIRO, janeiro. 2005, p. 1).

Longe de ser uma ação visionária e pioneira da cidade, a política de solidez financeira é um "passo a passo" definido pelo BIRD em sua nova estratégia para os governos urbanos e locais dos municípios. Estes passaram a compor uma nova política de fomento do Banco que ampliou sua "carteira de clientes", na transição dos anos 1990 para o novo século XXI. Alguns documentos e órgãos são representativos deste novo momento do BIRD, como as coalizões de cidades denominadas de $\mathrm{Ci}$ ties of Change e de Cities Alliance e o documento Cities in Transition. ${ }^{3}$

Conforme Arantes, estas duas coalizões:

são responsáveis por assessorar os países em desenvolvimento (antigo bloco socialista e terceiro mundo) na formulação de planos estratégicos para as suas cidades. Cities of Change adota a denominação "plano de ação para o desenvolvimento econômico local" (LED) e a Cities Alliance, "estratégia para o desenvolvimento da cidade" (CDS). A CDS é composta por um LED e uma "estratégia de governança urbana". A agenda da gestão empresarial das cidades aparece dispersa em diversos documentos e publicações do Banco, mas está consolidada em seu principal documento setorial vigente, o Cities in Transition (2000) e no texto sobre desenvolvimento econômico local produzido pela Cities of Change (2003). Em ambos os casos, a ideia de "transição" e mudança refere-se à passagem, entendida em termos evolutivos, da gestão centralizada pelo Estado (State-based) para a gestão de mercado (market-based), com alterações qualitativas no padrão de provisão dos serviços públicos, de financiamento das cidades e de governança (2004, p. 62).

Há uma matriz discursiva dos organismos internacionais e em especial do BIRD a respeito das novas estratégias voltadas para os governos urbanos locais que se expressa em dois planos, ambos de produção de sentido sobre a cidade: um primeiro, em que as políticas urbanas incorporam o "léxico financeiro corporativo";

\footnotetext{
${ }^{3}$ Aqui é utilizada a versão resumida do documento produzido pelo BIRD e traduzida para o espanhol: "Ciudades em transición. Resumen estrategia del Banco Mundial para los gobiernos urbanos y locales" (2000).
} 
e um segundo, baseado na "incorporação do vocabulário solidário-participativo para as novas políticas compensatórias de combate à pobreza" (ARANTES, 2004, p. 62).

Já se encontra presente no documento "Ciudades en Transición" um conjunto de princípios balizadores das políticas de desenvolvimento econômico local para as cidades e que define um novo marco de aprofundamento dos ajustes dos países subdesenvolvidos, como o Brasil. Assim, sob os títulos de "Boa Gestão de Governo e Administração" e "Solvência Financeira" encontram-se explicitadas, no documento, "as condições básicas da produtividade urbana, necessárias também para que as cidades se tornem competitivas e com aptidão empresarial no mercado mundial" (BANCO MUNDIAL, 2000, p.15). Quanto ao primeiro tema, são estimulados: o desenvolvimento de projetos urbanos financiados pelo BIRD como laboratórios práticos dos governos municipais, as parcerias público-privadas visando ao alargamento da participação do setor privado na prestação dos serviços urbanos e a concentração da ação do Estado em uma "gestão eficiente" "para que os pobres sejam beneficiados" (BANCO MUNDIAL, 2000, p. 17), intercâmbio de "boas práticas" e capacitação dos recursos humanos dos governos locais nas técnicas de gestão urbana.

Já no segundo tema, "solvência financeira", encontram-se as recomendações que permitem viabilizar a visão do BIRD sobre a equação "competitividade + cidadania plena". Isso significa tornar os trabalhadores pobres e os dos segmentos informais da economia contribuintes e clientes dos serviços públicos que, por recomendação do próprio banco, devem estar sob a responsabilidade das parcerias público-privadas. A cidadania inicia e se encerra na esfera do consumo e para tanto precisa de "bons cidadãos" que estejam inseridos nos procedimentos formais de consumo, de crédito, de recolhimento de impostos e taxas, nem que para isso seja necessário organizar novas políticas e sistemas específicos voltados para os segmentos mais pobres.

De forma esclarecedora, o BIRD define, no documento "Ciudades em Transición", o que vem a ser a solvência financeira necessária ao caráter equitativo e sustentável da economia de uma cidade:

Por solvência financeira se entende aqui a solidez financeira no tratamento das fontes de receitas e de gastos e, no caso de algumas cidades, uma capacidade creditícia tal que Ihes permita o acesso aos mercados de capitais [grifo nosso]. As operações de desenvolvimento urbano do Banco e o correspondente diálogo sobre políticas fomentam a adoção de sistemas claros e coerentes de receitas e de gastos locais, com transferências intergovernamentais transparentes e previsíveis, e prudência no endividamento do município, assim como contabilidade financeira, gestão de ativos e práticas de contratação aceitas. Para uma boa gestão das finanças urbanas é importante adotar um critério comercial para muitos dos serviços e as funções administrativas das cidades, sem perder de vista os interesses sociais. Este critério 
comercial também é indispensável para a participação do setor privado ou a privatização dos serviços urbanos (BANCO MUNDIAL, 2000, p. 19).

É oportuno observar que Arantes também identificou nas estratégias do BIRD a preocupação com a diversificação das formas de captação de recursos por parte dos governos urbanos locais, inclusive no mercado de capitais, a exemplo da ação da prefeitura do Rio de Janeiro:

O impasse imediato a ser enfrentado pela coalisão público-privada formada no Board municipal é a disparidade entre metas a serem alcançadas e escassez de recursos públicos para realizálas. Um tema crucial será o de "solvabilidade" das cidades (numa tradução do termo bankability). Os técnicos do Banco Mundial e também do BID formularão em diversos documentos a proposta de transformar os municípios em grandes tomadores de empréstimos no mercado privado de capitais, tal como hoje fazem os Estado nacionais. Ao pressionar os governos locais a terem um comportamento de responsabilidade fiscal, como vimos, na agenda de reformas dos anos 1980, o Banco pretende "encorajar a transição para o sistema municipal de crédito de mercado" [...]. A cidade-empresa deve amplamente sustentar-se num modelo de parcerias público-privadas (PPPs) para a implementação de novas infraestruturas, bem como na sua capitalização pela emissão local e internacional de títulos (municipal bonds), avaliados conforme indicadores de credibilidade (rates) e do "risco cidade" [...] (ARANTES, 2004, p. 65).

Na verdade, o que se vê mais intensamente a partir de 2000, é a verticalização, rumo aos municípios, dos programas de ajuste dos Estados latino-americanos, levados à frente nos anos 1990, e que possibilitaram, por exemplo no caso brasileiro, a instituição do Programa Nacional de Desestatização (PND). A partir deste processo, o que se viu no país, e nas esferas estaduais, foi uma avassaladora "transferência patrimonial", o desmonte do poder regulador do Estado, e a quebra do próprio sentido de "serviço público". Mas o elemento mais surpreendente e revelador dos destinos que se abririam para o país a partir de então foi saber que o programa que destruiu a base material de regulação do Estado, desativou milhares de postos de trabalho em todo o Brasil e deixou um legado de altos custos para o Tesouro Nacional e o BNDES foi financiado, de forma considerável, com recursos do Fundo de Amparo do Trabalhador (FAT).

A descentralização do PND para o restante do país seguiu as recomendações do BIRD por meio da "Estratégia de Assistência ao País", para o período 1998-2000. ${ }^{4}$

\footnotetext{
${ }^{4}$ Indica-se, para aprofundamento do tema, a coletânea da Rede Brasil "As Estratégias dos Bancos Multilaterais para o Brasil", que inclui a "Estratégia de Assistência ao País", elaborada em 6 de março de 2000 pelo BIRD. Da mesma forma, encontra-se incluído na coletânea o "Documento de País", elaborado pelo BID para o Brasil, em 7 de junho de 2000. A este respeito ver: Barros (2001).
} 
As ações propostas nesta estratégia ampararam-se no seguinte diagnóstico: "O ajuste das finanças do setor público está atrasado. É necessária a atenção essencial para melhorar o desempenho fiscal nos níveis subnacionais (estaduais) e para privatizar empresas públicas" (Banco Mundial, 1997, p. 125). As ações planejadas a partir deste diagnóstico recomendaram:

- Gastos públicos: reduzir despesas com trabalho após a reforma do funcionalismo público;

- Impostos: melhorar sistema de impostos sobre valores agregados;

- Previdência social: introduzir sistema financeiramente viável;

- Bancos: fortalecer a supervisão, reduzir o papel dos Bancos Estaduais através da privatização e reestruturação;

- Continuar o programa de privatização para outras empresas federais e estaduais públicas (BANCO MUNDIAL, 1997, p. 126).

O governo do estado do Rio de Janeiro, por meio da figura do então governador Marcelo Alencar (PSDB), obteve uma linha de financiamento do Banco Mundial, ${ }^{5}$ em 1997, no valor de US\$ 250 milhões, para encaminhar o Programa Estadual de Desestatização (PED). O exercício de um governo local que teve como partido o mesmo PSDB do então presidente Fernando Henrique Cardoso, colocou o Rio de Janeiro como verdadeira antessala do PND. Não casualmente, o Rio foi o primeiro estado a implantar o PED e a criar uma "Agência Reguladora de Serviços Públicos Concedidos do Estado do Rio de Janeiro" (ASEP-RJ), em 1997. No início deste processo de "desestatização", foram incluídas 27 empresas no PED. O saldo deste processo, no final dos anos 1990, foi o desmantelamento da base pública dos serviços de infraestrutura urbana e a privatização do Banco do Estado do Rio de Janeiro (BANERJ). Entre as 27 empresas inicialmente arroladas, podem-se citar as seguintes desestatizações: Cia. de Navegação do Estado do RJ (CONERT); LIGHT e Cia. de Eletricidade do Rio de Janeiro (CERJ); Cia. do Metropolitano; Cia. de Desenvolvimento Rodoviário e Terminais do Estado do RJ; Cia. Estadual de Gás do RJ e RIOGÁS; Trecho rodoviário de ligação entre os municípios de Rio Bonito, Araruama, São Pedro da Aldeia; Cia. Fluminense de Trens Urbanos-FLUMITRENS; Telecomunicações do Rio de Janeiro (TELERJ); Banco do Estado do Rio de Janeiro (BANERJ).

O que se pretende destacar é que a privatização de empresas estatais responsáveis por serviços urbanos tem um efeito direto sobre os municípios do estado do Rio de Janeiro. Ou seja, os efeitos sobre a urbanidade são desigualmente distribuídos quando se consideram, por exemplo, a qualidade dos serviços prestados e os custos das tarifas. Tal questão torna-se ainda mais complexa frente à dimensão metropolitana dos fenômenos urbanos, como é o caso da questão do saneamento. A este respeito, estudo de BRITO e PORTO (1998) discute os impactos sociais causados pela introdução do modelo de privatização nos serviços públicos de saneamento prestados por empresas estatais, no Brasil, como o caso da CEDAE (Compania

\footnotetext{
${ }^{5}$ Segundo o Banco Mundial, o montante de recursos previstos pelo governo do estado do Rio para o Programa Estadual de Desestatização estava estimado, à época, em US\$ 5.9 bilhões.
} 
Estadual de Água e Esgoto), no estado do Rio de Janeiro. Tal empresa esteve arrolada entre as estatais a serem privatizadas por meio do PED, durante o governo de Marcelo Alencar. Contudo, medida legislativa da Câmara Municipal do Rio de Janeiro conseguiu retirar a CEDAE do elenco das empresas arroladas no PED.

Entre os impactos de tal processo, desigualmente distribuídos no território, Brito e Porto salientam:

Os serviços deixam de ser orientados por uma lógica de serviços para todos, para se guiarem por uma lógica de rentabilidade, reforçando a questão da capacidade de pagamento dos usuários. Na prática, as empresas privadas vêm privilegiando certas categorias de usuários e certas zonas do território e negligenciando outras. Aos poucos, estabelece-se um processo marcado, por um lado, pela disputa das grandes empresas privadas que prestam serviços, em torno das áreas mais rentáveis ou em acelerado crescimento. Por outro, marcado também pelo desprezo por áreas mais pobres, que nem são grandes consumidores de serviços, nem utilizam tecnologia sofisticada. Esses usuários são obrigados a pagar tarifas elevadas pelos serviços de base; e, se não têm condições de pagar, acabam excluídos do acesso (BRITO e PORTO, 1998, p. 73).

Ainda sobre o mesmo tema, os referidos autores destacam a dimensão metropolitana desta problemática e seu alto grau de heterogeneidade intrametropolitana, além das pressões existentes sobre a permanência da política dos subsídios públicos para acesso aos serviços de saneamento, por parte da população de baixa renda:

Em ambientes tão heterogêneos como são as regiões metropolitanas brasileiras, nas quais cidades ricas estão umbilicalmente ligadas a cidades pobres, e nas quais, em uma mesma cidade, bairros ricos e bem servidos de serviços e infraestruturas convivem com áreas de pobreza absoluta e ausência total dessas mesmas infraestruturas, não é simples a entrada do setor privado na exploração dos serviços de água e esgoto. [...] Partes que hoje podem almejar ter acesso aos serviços graças ao sistema de subsídios cruzados que vem orientando a gestão pública, cujo princípio norteador não é o lucro. Em uma estrutura de prestação de serviços privada, voltada para o lucro, os subsídios cruzados são eliminados, e o fornecimento de água a populações de baixa renda torna-se um impasse [...]. Faz-se portanto necessária [...] a identificação das cidades que podem pagar, e, dentro delas, das áreas rentáveis (BRITO e PORTO, 1998, p. 77).

A partir do exposto neste segmento do texto, verifica-se que o direito à cidade nem mesmo se colocou como questão pertinente ao debate dos destinos da "coisa pública". Muito menos foi encaminhada qualquer discussão sobre a dimensão ter- 
ritorial destes serviços urbanos que se inserem em diferentes espaços geográficos do estado, para além da dimensão metropolitana do problema. Desnecessário também dizer que não se enfrentou antecipadamente a questão do marco regulatório destes serviços a partir da sua privatização.

\section{O Diálogo entre o II PECRJ e a Agenda}

\section{do Bando Mundial para o Futuro da Cidade do Rio de Janeiro}

O ano de 2001 marcou o retorno do prefeito César Maia ao governo da cidade e o aprofundamento do planejamento estratégico do Rio de Janeiro, agora sob a sua segunda versão denominada "As Cidades da Cidade", em referência à perspectiva do desenvolvimento econômico endógeno de suas regiões, vistas como cidades dentro da cidade.

O II PECRJ teve seu lançamento oficial realizado em 4 de outubro de 2001. Tal plano passou a perseguir essa ideia do desenvolvimento endógeno das regiões da cidade. Essa, por sua vez, estava pautada pelo conceito de microdesenvolvimento e da metodologia do desenvolvimento econômico local difundida pelo BIRD. De acordo com o "Programa de Desenvolvimento Econômico de Microrregiões da Cidade do Rio de Janeiro":

O desenvolvimento de um local depende, às vezes, de pequenos projetos ou articulações que têm o poder de multiplicar, ampliar, atrair novos negócios, impulsionar os setores produtivos ou desenvolver o empreendedorismo focado no desenvolvimento daquele local específico.

[...] O programa pretende viabilizar, a partir da identificação com pontos de potencial localizados nas diversas regiões da cidade, a realização de pequenas obras e a implantação de pequenos equipamentos ou serviços que promovam o desenvolvimento do local, não só por meio de um trabalho conjunto dos diversos órgãos municipais, mas também em parceria com os governos estadual e federal e a iniciativa privada.

A partir da identificação das áreas [...] a Prefeitura atuará, por meio da Sedect, buscando implantar esses equipamentos e/ou serviços, para que aquele ponto possa desenvolver todo o seu potencial econômico, gerando trabalho e renda, melhorando o ambiente construído e criando locais de convivência dos moradores (PREFEITURA DA CIDADE DO RIO DE JANEIRO, 2003, pp. 1-2).

A concepção acima busca associar a ideia de arranjos produtivos locais à perspectiva de projetos urbanos de desenvolvimento local sem, contudo, abdicar do modelo de intervenção dos grandes projetos urbanos estratégicos. O II PECRJ é a expressão desta convergência e é por meio dele que o Programa de Desenvolvimento Econômico de Microrregiões se operacionaliza.

Herdeiro da tradição inaugurada pelo I PECRJ na forma de conceber, planejar e gerir a cidade, o II PECRJ presta sua "homenagem" ao seu antecessor, ao mesmo 
tempo em que estabelece novas dinâmicas de atuação sobre a cidade, com destaque para o chamado planejamento regional. Assim, o II PECRJ elaborou um plano estratégico para cada uma das doze regiões que correspondem, respectivamente, à base territorial das subprefeituras da cidade (Bangu, Barra da Tijuca, Campo Grande, Centro, Grande Méier, Ilha do Governador, Irajá, Jacarepaguá, Leopoldina, Tijuca/ Vila Isabel, Zona Norte e Zona Sul).

Em todos os doze planos, foram elaborados objetivos centrais, estratégias, objetivos específicos e propostas de atuação que serão melhor analisados no último segmento do texto. É deste material que tanto o programa de desenvolvimento microrregional quanto o orçamento participativo (OP) retiram suas propostas. Ou seja, o PECRJ continua a ser a principal referência de planejamento urbano da prefeitura para a cidade, subordinando, inclusive, outros instrumentos de gestão democrática, como o orçamento participativo.

Enquanto o I PECRJ sofreu a influência direta dos consultores catalães, por meio da empresa "Tubsa - Tecnologies Urbanes de Barcelona S.A.", o II PECRJ trouxe a marca da influencia do BIRD, a partir de sua entrada mundial no "mercado do planejamento estratégico". Isso não significa, contudo, o abandono das influências anteriores. Pelo contrário, a agenda de ajuste urbano do BIRD não apenas se articula às práticas de empreendedorismo urbano do I PECRJ, como as potencializa. Tal realidade pode ser melhor dimensionada por meio das propostas de desenvolvimento econômico local produzidas pelo banco acerca da cidade. Tais propostas articulamse ao programa Cities of Change, do Banco Mundial, executado nos anos de 2001 e 2004, responsável por agregar redes de cidades consideradas sub-desenvolvidas da Europa Central e do Leste com o objetivo de difundir a metodologia do desenvolvimento econômico local (DEL) proposta pelo banco. Segundo o BIRD, o referido programa objetivava:

fortalecer a capacidade dos municípios para realizar planejamentos estratégicos e desenvolver planos de ação; estimular o intercâmbio de boas práticas entre os municípios para facilitar o acesso à experiências e conhecimentos internacionais; e facilitar a divulgação dos resultados (BANCO MUNDIAL, 2006, p. VI).

Ainda sobre a definição do DEL, o banco assim se manifesta em seu manual dedicado ao tema:

O propósito do desenvolvimento econômico local (DEL) é construir a capacidade econômica de uma determinada área para melhorar sua perspectiva econômica e a qualidade de vida de todos. Este é um processo pelo qual os parceiros públicos, o setor empresarial e os não-governamentais trabalham coletivamente para criar condições melhores ao crescimento econômico e à geração de emprego. [...] A capacidade das comunidades para meIhorar a qualidade de vida, criar novas oportunidades econômicas e lutar contra a pobreza, depende de essas serem capazes de 
compreender os processos de DEL e agirem estrategicamente no mercado que muda constantemente e que é cada vez mais competitivo. Os empreendimentos privados bem sucedidos e as parcerias público-privadas (PPP) geram riqueza nas comunidades locais. No entanto, as empresas privadas requerem um ambiente favorável aos negócios para gerar prosperidade. O governo municipal tem o papel fundamental de criar um ambiente favorável para o desenvolvimento e o sucesso dos negócios. Pela sua natureza, o desenvolvimento econômico local é decorrente de uma parceria entre o setor de negócios, os interesses da comunidade e o governo municipal (BANCO MUNDIAL, 2006, p. 1).

No ano de 1999, o BIRD elaborou um documento intitulado "Rio de Janeiro: um estudo da cidade (partes I e II)", publicado pela Prefeitura, no ano de 2002, na coleção "Estudos da Cidade". Nesse documento, logo em seu primeiro parágrafo, é exaltada a primeira gestão do prefeito César Maia como exemplo de retomada do dinamismo da cidade após um longo período de crise. Nas palavras do banco, César Maia é considerado um "prefeito ativista".

Da mesma forma, sem muitos rodeios, o BIRD afirma o novo lugar da cidade no contexto nacional e define seus objetivos com o estudo do Rio de Janeiro. Tal definição produz um sentido de desenvolvimento que se encontra alinhado à definição metodológica de DEL que os planejamentos estratégicos devem executar:

O governo municipal que, no passado, atuou principalmente no planejamento e desenvolvimento urbano, agora está sendo pressionado a começar a desempenhar um papel importante na promoção do crescimento econômico da cidade e no projeto de redes de segurança para os menos favorecidos da cidade. [...] Os objetivos do estudo são ajudar o governo municipal a conceber políticas e programas para:

- restaurar o crescimento econômico em base ampla e sustentálo acima da média nacional ao mesmo tempo reduzindo sua volatilidade;

- combater a pobreza através de melhor direcionamento, de tal modo que enquanto os índices agregados de pobreza sejam reduzidos por meio de um crescimento mais rápido, aqueles que permanecem na pobreza recebam assistência apropriada;

- manter a disciplina fiscal, estabelecendo fronteiras apropriadas para a Prefeitura que ajudem a melhorar a qualidade dos serviços municipais ao mesmo tempo em que mantenham a proporção de dívida e receita corrente abaixo de um (BANCO MUNDIAL, 2001, p. 9).

A agenda do BIRD "para o futuro" do Rio enfatiza a necessária mudança do perfil de dependência econômica da cidade em relação ao governo federal, princi- 
palmente em termos de financiamentos internos e transferências. A solução estaria no incremento das parcerias público-privadas. Por isso, o banco é "efusivo" em sua avaliação positiva sobre o I PECRJ.

De forma análoga, com repercussões diretas sobre o ajuste fiscal da cidade, está o incentivo à disseminação do princípio de focalização das políticas sociais e dos serviços urbanos, de forma a fazer refluir o princípio da universalização na estruturação das políticas públicas e abrir o "mercado" às parcerias privadas - medidas essas que, segundo o BIRD, tornam-se necessárias principalmente frente ao contexto de transferência de responsabilidades sociais e urbanas para as municipalidades, aberto a partir de 1988, o que contribui para o déficit fiscal local. A focalização é o princípio que assegura ao poder público que os recursos não "vazarão" de forma significativa para os não-pobres, conforme afirmação do próprio banco.

Seguindo a classificação do BIRD quanto aos tipos de programas e coberturas sociais, chega-se aos três recortes: 1) universal; 2) moderadamente direcionado; e 3) direcionado aos pobres. Ainda de acordo com o banco:

Existe uma variação considerável na cobertura, estabelecimento de alvos e benefícios por família desses e outros programas, muitas vezes por motivos justificáveis. Os gastos municipais com água e esgoto, remoção de lixo sólido e saúde básica não são direcionados, são universais, e os gastos por família são pequenos. Programas tais como educação básica e melhoramentos urbanos são moderadamente direcionados e seus gastos por família são grandes; a diferença entre esses programas está em que enquanto a educação básica alcança mais de $80 \%$ dos pobres, o principal programa de melhoramentos urbanos da cidade - o Favela Bairro - atinge no máximo 10\% dos pobres. O terceiro conjunto de programas é daqueles dirigidos aos pobres, como o Rio Criança Maravilhosa e a Bolsa Alimentar, dos quais mais de $70 \%$ do gasto total vai para os pobres, os gastos por família são moderados, mas a cobertura dos lares permanece abaixo de $30 \%$ [...]. Expandir programas selecionados com enfoque na pobreza, aumentar a cobertura no terceiro conjunto de programas é em potencial a melhor alternativa através da qual a Prefeitura pode ajudar os mais pobres da cidade do Rio, desde que o vazamento para os não-pobres seja mantido baixo (BANCO MUNDIAL, 1999, p. 5).

O conjunto da agenda do BIRD para o ajuste urbano da cidade do Rio de Janeiro e, em especial, a avaliação e a recomendação do banco acerca da associação entre eficiência das políticas sociais e a sua focalização para a população pobre urbana, adquire maior significado quando considerado o contexto atual de crescimento do desemprego e das formas de trabalho não-assalariado.

A metamorfose da periferia e o discurso da sua integração nos circuitos internacionais do desenvolvimento capitalista operam em nome de uma dada visão de 
"democracia". Uma espécie de cenário em que as "ideias estão fora do lugar" revela os limites da democracia aliada à competitividade das cidades. Trata-se de uma visão de cidadania que reivindica como seu sujeito o indivíduo maximizador do espírito empreendedor e racionalizador das exigências e atributos da competitividade social. Aqui, a maximização é dupla. Trata-se de potencializar tanto o "sujeito empreendedor" do trabalho, quanto a "cidade empreendededora". Como seus contrapontos estão os segmentos sociais que não se apropriam dos novos termos da "gramática social" competitiva das cidades ou o fazem de forma subalterna. Para estes, a cidade oferece a sua face de integração focalizadora que cria, de forma minuciosa e exaustiva, os lugares sociais da exceção (OLIVEIRA, 2003). É a partir dessa face que a pobreza urbana é enxergada. Mas é também através do seu olhar constantemente renovado de criminalização da pobreza que a cidade reivindicará a distância e a segurança necessárias frente aos seus pobres, sempre que as condições que a tornam uma cidade competitiva forem ameaçadas.

Há muito mais elementos a viabilizar o "ajuste urbano" $^{6}$ da cidade pelas agências e organismos internacionais que atuam na escala territorial das redes transnacionais. Contudo, o desdobramento do plano estratégico em sua segunda versão, referente ao período de 2001-4, aprofundou este largo processo ao reproduzir a mesma concepção de cidade do I PECRJ.

\section{A Anulação da Política Frente ao Ajuste Urbano da Cidade:}

\section{a Submissão do Orçamento Participativo ao II PECR]}

É importante descrever a organização e a estrutura do II PECRJ e como este se entrelaça ao I PECRJ. Do ponto de vista da sua estrutura e organização, o plano contou com uma equipe técnica central formada por técnicos da própria Prefeitura; com coordenadores dos planos regionais que são membros da equipe técnica central; com os subprefeitos no trabalho de organização e mobilização das comissões regionais (vale lembrar que os subprefeitos não são eleitos pela população do Rio de Janeiro e sim indicados pelo Prefeito), além do trabalho em parceria com a equipe técnica central; e com doze comissões regionais compostas pela sociedade civil.

A participação da sociedade civil foi registrada pelo II PECRJ por meio de uma lista de membros individuais e de entidades presentes em alguma das reuniões regionais. Algumas informações se destacam na leitura das lista, a começar pela ausência de qualquer representação de entidades sindicais em alguma das comissões regionais. Da mesma forma, não há uma representação significativa de entidades de representação do setor empresarial. Há, nesse aspecto, a predominância da participação da Associação Comercial do Rio de Janeiro, que se faz representar em todas as comissões regionais do plano. As Associações de Moradores também se fizeram presentes de forma pouco significativa, principalmente do segmento das Associações de Moradores das Favelas. A maior participação de entidades e esta-

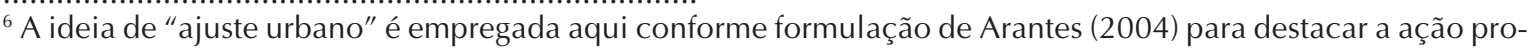
gramática de agências multilaterais como o BIRD e o Banco Interamericano de Desenvolvimento na construção de uma agenda de "boa governança" dos países subdesenvolvidos, em especial das cidades latino-americanas.
} 
belecimentos ocorreu no segmento da própria administração pública, por meio dos diferentes órgãos da prefeitura, como secretarias, subsecretarias, fundações, Regiões Administrativas, escolas municipais etc.

A partir da estrutura referida anteriormente, foram organizados os "segmentos" do plano (planos regionais, orçamento participativo, articulação entre os planos, impulsão, monitoramento, avaliação, atualização do plano geral, observatório) articulados a etapas correspondentes, compondo a dinâmica operacional. No segmento de elaboração dos planos regionais, por exemplo, foram estruturadas seis etapas, a saber: sensibilização, pré-diagnóstico, diagnóstico, estratégias, projetos e homologação. Foi a partir dessa dinâmica de etapas que as comissões regionais foram constituídas e chamadas a homologar, ao final, suas propostas de planos estratégicos. Para além do aspecto formal dessa estrutura e organização, há que se destacar o processo acelerado de encaminhamento das discussões no âmbito das regiões e a pouca divulgação nos bairros de abrangência das subprefeituras.

O II PECRJ foi lançado e apresentado oficialmente à cidade em 4 de outubro de 2001 em solenidade que contou com as presenças do prefeito César Maia, do então ministro de Ciência e Tecnologia Ronaldo Mota Sandenberg, de representantes de instituições de pesquisa e universidades, de entidades públicas e privadas e diferentes convidados. Essa foi a primeira de uma série de quatorze reuniões (doze em cada região e uma com a comunidade acadêmica e científica) da etapa de sensibilização do II PECRJ.

É importante destacar que cada reunião regional, articulada às etapas do plano, seguiu uma agenda anterior de trabalhos preparatórios. Nesses trabalhos, a população não esteve presente, contando basicamente com os técnicos e subprefeitos. Da mesma forma, o momento de "encontro" entre a equipe central do II PECRJ e a população participante de cada comissão regional foi sempre instrumentalizado por recursos tecnológicos de informação de alto impacto performativo, com a finalidade explícita de acelerar ao máximo as discussões e alcançar mais facilmente o consenso necessário, sempre com o objetivo de realizar apenas uma reunião por etapa. Ou seja, o processo do II PECRJ perseguiu a mesma visão de "cidade pátria" do I PECRJ, apelando ao espírito cívico da corresponsabilidade pelos destinos da cidade, mas francamente refratária e diluidora dos espaços de diálogo público por que o conflito e o dissenso poderiam ser vistos, ouvidos e regulados coletivamente. Estes foram sempre subordinados a uma das formas de manifestação técnica do "diálogo cívico": a planilha, os mapas e dados fundamentados em técnicas de geoprocessamento, as agendas positivas e negativas, os gráficos e tabelas com os resultados do inquérito qualitativo, além dos inúmeros recursos tecnológicos acionados pelos programas de computadores:

As informações analisadas e utilizadas permitiram a identificação das ameaças e oportunidades das regiões, fundamentais no processo. Equipamentos como telões, flip-charts, cartazes conceituais e projetores conectados a computadores portáteis foram instrumentos que levaram para as reuniões informações previamente pormenorizadas, permitindo que as comissões 
elaborassem o trabalho de cada etapa em apenas uma reunião. As projeções simultâneas permitiram a obtenção de resultados consensuais de maneira mais rápida. A etapa foi sendo construída e elaborada, com a participação direta da audiência, até a obtenção de resultados consensuais, aprovados na mesma reunião, viabilizando desta forma a realização dos planos regionais em um curto espaço de tempo (PREFEITURA DA CIDADE DO RIO DE JANEIRO, 2002, p. 25).

A participação da "audiência" só é possível de ser limitada ao curto espaço de tempo se for disciplinada. Daí a produtividade associada aos dispositivos técnicos do planejamento estratégico, mais do que a ideia de um poder que diz não. A função destes é acima de tudo disciplinadora e viabilizadora do consenso necessário à rápida aprovação de cada etapa do plano. É de fundamental importância que se préestabeleça não a quantidade da participação (quantos poderão ou não estar presentes), mas os termos, os balizamentos que irão indicar o que é possível ou não de ser incluído como pertinente ao debate. Contudo, o dissenso democrático advém não da quantidade, mas da qualidade da relação que se pretende instituir politicamente. Ao focar as relações sociais entre Estado e sociedade civil e entre a própria sociedade como relações entre "parceiros" e "colaboradores", o que se opera é a anulação da própria capacidade de subjetivação política, como afirma Rancière (1996). A este respeito é importante a interlocução com este autor para pensar o significado de tais práticas de anulação das "cenas polêmicas" da política da e na cidade:

Uma subjetivação política é uma capacidade de produzir essas cenas polêmicas, essas cenas paradoxais que revelam a contradição de duas lógicas, ao colocar existências que são ao mesmo tempo inexistências ou inexistências que são ao mesmo tempo existências. [...]

É assim que o relacionar duas coisas sem relação torna-se a medida do incomensurável entre duas ordens [...]. Mas esses incomensuráveis estão bem medidos um no outro. E essa medida refigura as relações das parcelas e das partes, os objetos passíveis de provocar litígio, os sujeitos capazes de articulá-lo. Ela produz, ao mesmo tempo, inscrições novas da igualdade em liberdade e uma esfera de visibilidade nova para outras demonstrações. A política não é feita de relações de poder; é feita de relações de mundos (RANCIÉRE, 1996, pp. 52-4).

Se por um lado é possível demarcar esta concepção de "consenso" como um conteúdo transversal aos dois planos, por outro lado há que se demarcar uma inflexão importante operada pelo II PECRJ, qual seja: o fundamento teórico e ideológico do desenvolvimento local endógeno opera sob uma base fortemente dependente do discurso da participação. De fato, a segunda experiência do plano estratégico toma a participação local como uma variável central da própria ideia de de- 
senvolvimento. Ou melhor, na tentativa de aliar competitividade e cidadania, as estratégias e políticas de desenvolvimento local endógeno buscam unir "as capacidades técnicas, financeiras e gerenciais locais, o associativismo e potencial empreendedor, a democracia participativa entre atores sociais e instituições" (MOREIRA BRAGA, 2001, p. 28).

Para permanecer na "chave interpretativa" oferecida por Moreira Braga, o II PECRJ evidencia os limites destes fundamentos teóricos e ideológicos e, de forma mais ampla, os limites de se buscar equalizar cidadania e competitividade. A busca de "equalização" dos conflitos se baseia na concepção de uma "distorção", no máximo passageira, entre os dois campos de práticas (que, por definição, são sempre dissonantes). Esta busca por equalização, por dissipação, por formas de anulação de cenas de conflito - como se estas fossem a negação da política e não um de seus fundamentos - revela o quanto esta concepção de desenvolvimento local é dependente de um regime de consenso e de um regime de opinião, conforme os termos de Rancière (1996), de tal forma que entre as práticas da cidadania e as da competitividade deve-se produzir uma equação sem "restos" que possibilite colocar em evidência a imagem de uma comunidade idêntica a si mesma.

Um outro elemento importante a destacar é a ausência da discussão de outras escalas espaciais, notadamente a metropolitana, dos temas e questões objetos do debate, de tal forma que as concepções de desenvolvimento endógeno, desenvolvimento econômico microrregional, espaço local, regiões, entre outras formuladas pelo II PECRJ, reiteram o mesmo padrão de discussão das cidades de forma autônoma e fragmentada como o verificado no I PECRJ. Repetindo, inclusive, a contradição de conceber a cidade como espaço mundial, reivindicando sua condição de cidadeglobal e, ao mesmo tempo, manter a miopia para a dimensão metropolitana da cidade do Rio de Janeiro, de seus problemas e de suas necessárias propostas de solução. Cabe destacar que este "encapsulamento" é um clássico padrão da história de desenvolvimento do Rio de Janeiro, antes mesmo da República. Algo que Lessa (2001) já qualificou como uma espécie de comportamento da cidade "virar as costas" ao interior fluminense, ao longo dos seus diferente formatos jurídico-institucionais na trajetória da nação:

Desde 1834, com a delimitação do Município Neutro, os barões do café podiam exercer na Província Fluminense seus poderes como os oligarcas locais mais poderosos do país. [...] Por outro lado, o Município Neutro separado da Província, facilitava a administração direta da cidade pela Coroa. Esta separação foi, a longo prazo, historicamente cruel para o interior fluminense. A decadência da cafeicultura não estagnou a cidade nem foi assumida pelo Distrito Federal como um problema regional. A urbanização prosseguiu e a centralidade do Rio foi imune à crise do interior. É inquestionável a confirmação da capitalidade e centralidade do Rio pelo café escravo. A cidade/capital continuou crescendo e prosperando sem assumir o papel político de protetora e reanimadora de sua retaguarda regional. Voltou suas 
costas para o drama fluminense. A Guanabara chegou a formular uma política antifluminense. Somente com a fusão dos dois estados, feita à força em 1975 pelo governo autoritário, teve início a difícil e ainda inconclusa rearticulação política econômica regional (LESSA, 2001, pp. 121-3).

Voltando à dinâmica do II PECRJ, ${ }^{7}$ de uma forma geral, a metodologia das etapas subsequentes de pré-diagnóstico e diagnóstico seguiu a mesma orientação do I PECRJ, dividindo a avaliação da cidade em dois campos chamados de retratos em positivo e em negativo, organizados a partir de dados extraídos de um inquérito qualitativo realizado por região. Em média foram aplicados cento e quinze questionários por região. De forma a complementar os retratos diagnósticos regionais, foram elaboradas duas planilhas chamadas de "agendas ajuda". A primeira, aplicada nas reuniões do pré-diagnóstico, foi composta por temas críticos extraídos da avaliação do "retrato em negativo" de cada região. Seu conteúdo se subdividiu em quatro itens: debilidades, propostas, grupos de trabalho por tema e eleição de um coordenador para cada grupo. A segunda agenda, voltada para a etapa do diagnóstico, teve a mesma apresentação na forma de planilha, mudando apenas os itens a serem discutidos: vocações, potencialidades, manifestações culturais e linhas estratégicas. Todos os três primeiros itens foram previamente elaborados pela equipe central do II PECRJ, restando às comissões regionais a tarefa principal de elaborar as linhas estratégicas e de definir a feição inicial dos objetivos centrais que estruturaram cada um dos doze planos estratégicos.

As etapas quatro (estratégias) e cinco (projetos) intensificaram a dinâmica anterior de realização de trabalhos preparatórios às reuniões regionais sob a responsabilidade da equipe central do II PECRJ. De tal forma que a complexidade das tarefas exigidas aumentou de forma proporcional ao esvaziamento dos espaços reais de discussão da população. Tudo isso, é bom lembrar, mantendo a meta de uma reunião por etapa, o que exigiu a tomada de decisão por parte da equipe técnica central sobre temas relevantes, ainda que estes tenham retornado aos espaços das comissões regionais sob a forma de mais planilhas, gráficos, cartazes conceituais etc.

Os trabalhos preparatórios à etapa quatro (estratégias) culminaram com a elaboração de um amplo material que incluiu: a definição do objetivo central para cada plano estratégico regional, a definição preliminar de estratégias, a definição de objetivos específicos de acordo com cada estratégia formulada, a sistematização das propostas de ação elencadas pelos grupos temáticos (que ocorreram na etapa de prédiagnóstico) e a elaboração de mais uma "agenda ajuda" com o quadro dos objetivos específicos, propostas de programas ou projetos e parcerias possíveis. As reuniões

\footnotetext{
${ }^{7}$ Foi a partir do ritual dos procedimentos do II PECRJ que se operou a metamorfose do orçamento participativo da cidade. A explicitação de tal dinâmica possibilita tirar dos "campos cegos" algo que só é possível de ser enxergado por meio do mapeamento das práticas sociais da cidade. E estas práticas de planejamento estratégico, quando incorporam a "participação" da sociedade civil, fazem-no subordinando-a ao ritual técnico-operativo que é uma das condições de possibilidade de se obter uma participação burocrática subsumida à norma do plano.
} 
das comissões regionais tiveram a tarefa de alterar alguns desses elementos, se assim o avaliassem, e identificar de forma preliminar as parcerias necessárias a cada projeto de ação.

As etapas cinco (projetos) e seis (homologação) foram de importância fundamental, pois materializaram a subordinação da política do orçamento participativo (OP) ao II PECRJ. A equipe técnica central do II PECRJ dividiu as reuniões das duas etapas em dois grandes momentos: um primeiro relativo ao II PECRJ, de forma geral, dedicado ao fechamento e à aprovação do conjunto dos objetivos gerais, das estratégias e seus objetivos e dos projetos específicos; ${ }^{8}$ e um segundo voltado especificamente para o OP.

A dinâmica do OP adotada nas duas etapas envolveu a apresentação, pela equipe técnica central, de uma lista previamente selecionada e contendo sete temas prioritários entre os treze temas ${ }^{9}$ existentes no orçamento municipal. A eleição destes sete temas obedeceu à metodologia do OP definida pela deliberação n. 001, de 10 de junho de 2002 (PREFEITURA DA CIDADE DO RIO DE JANEIRO, 2002). Assim, Para cada um dos sete temas, as comissões regionais tiveram a tarefa de eleger, em ordem de prioridade, até três propostas de ação para inclusão no OP, totalizando, inicialmente, 21 propostas por região (252 no total das regiões).

Contudo, de acordo com a referida deliberação n. 001, a denominada Comissão Executiva Provisória do OP possuía a atribuição de pontuar os sete temas do OP de acordo com as prioridades indicadas nas propostas de ação das comissões regionais do PECRJ. A partir dessa organização hierárquica dos temas por pontuação, a Comissão Central Provisória do OP elegeu os cinco temas mais prioritários no conjunto das regiões, a saber: 1) desenvolvimento econômico, 2) saúde, 3) cultura, 4) meio ambiente, 5) esporte e lazer. Deste conjunto, foram finalmente extraídas as três propostas por tema, somando quinze propostas por região e 180 no total das doze regiões.

Após a aplicação dos critérios de viabilidade técnica e financeira pela instância máxima do OP, que é a Comissão Central, foram incluídos 55 projetos no orçamento municipal de 2003. Em termos de valores orçamentários, estes projetos foram estimados em $\mathrm{R} \$ 90$ milhões, representando 1\% do orçamento municipal de 2003 (R\$ 8.403.839.056,00). As propostas não-incluídas para o orçamento de 2003 permaneceram em uma espécie de "banco de propostas regionais" à espera do processo do OP dos próximos anos, logo, sem nem mesmo repetir a dinâmica praticada no ano de 2002; produzir uma nova dinâmica anual de OP; ou, ainda, o que seria o correto, atender às reivindicações da sociedade civil organizada - como as manifestadas pelo Fórum Popular do Orçamento, para o cumprimento da legislação do OP no município - a Prefeitura do Rio limitou o processo do OP da cidade, para

\footnotetext{
${ }^{8}$ Os doze planos estratégicos regionais que integram o plano "As Cidades da Cidade" formularam 68 estratégias que geraram 1.151 propostas. Entretanto, de acordo com o documento do II PECRJ, "estão sendo definidos critérios para priorização dessas propostas, no sentido de orientar as fases de impulsão e monitoramento." (PREFEITURA DA CIDADE DO RIO DE JANEIRO, p.15)

${ }^{9}$ Os treze temas do orçamento municipal do Rio de Janeiro são: educação, cultura, esporte e lazer, saúde, higiene, assistência social, transporte, trânsito, desenvolvimento econômico, urbanismo, habitação, saneamento e meio ambiente.
} 
o ano de 2004, e daí em diante à retirada de propostas do referido "banco". Afinal, não poderia ser de outra forma. A democracia concebida pelo II PECRJ e seu "ilusionismo" de OP não é dependente e nem produtora de espaços públicos e, ao mesmo tempo, não depende da "incômoda" presença de sujeitos políticos. Por isso, pode caber em uma "caixa de sugestões" ou um outro equivalente como um "banco de sugestões":

Para o orçamento de 2004, utilizaram-se os mesmos critérios adotados no Orçamento Participativo de 2003 e como resultado, foram aprovados mais 63 projetos, totalizando, até a presente data, 118 projetos dos Planos Estratégicos Regionais incluídos no orçamento municipal (PREFEITURA DA CIDADE DO RIO DE JANEIRO, p. 20).

As propostas do Plano Estratégico foram concebidas em um processo consensual e dentro de uma visão estratégica para o futuro das regiões. Entendemos que as propostas a serem priorizadas no OP devem continuar a ser escolhidas no elenco de propostas dos Planos Estratégicos Regionais, até que se esgotem (PREFEITURA DA CIDADE DO RIO DE JANEIRO, p. 218).

Cabe destacar que a Prefeitura do Rio de Janeiro, mesmo subordinando o OP ao PECRJ, viu-se obrigada a obedecer à determinação legal de instituição dos processos eleitorais para a composição das instâncias organizativas do OP. Assim, além da escolha das propostas para o $\mathrm{OP}$, as comissões regionais elegeram um membro de cada comissão para integrar, de forma paritária, a Comissão Executiva do OP, junto com os demais membros representantes do poder executivo. Para concluir o processo eleitoral das instâncias organizativas do OP, a etapa de homologação do II PECRJ conduziu à eleição dos representantes da sociedade no Conselho Popular do OP de 2004. Em conformidade com a legislação, os representantes foram eleitos de acordo com as Unidades Espaciais de Planejamento (UEP's) da cidade, que totalizam 55.

Não obstante o vocabulário técnico e conceitual do II PECRJ pretender apontar para algum influxo na forma de pensar e praticar a cidade, logo esta primeira impressão se desfaz quando se volta a atenção para o processo de orçamento participativo.

O que se quer evidenciar com a subordinação desta prática de inspiração democrática à lógica e à dinâmica de funcionamento do II PECRJ, é a anulação da política. Ou, nos termos de Hannah Arendt (1999), é a anulação da pluralidade necessária à sustentação da condição humana do próprio mundo como fenômeno político. E esta pluralidade, necessária à sustentação da palavra e da ação, não ocorre fora de um campo de aparência/visibilidade, ou seja, fora de uma esfera pública. Os rituais de participação que se estabelecem para a produção do "mesmo", de homogeneidades, de opiniões indistintas não possibilitam mais do que a agregação física. No sentido Arendtiano (1999) são esvaziados de "poder".

É possível identificar o momento em que ocorreu a subordinação da política à gestão da cidade e, o mais importante, a forma como isso se operou dentro do 
próprio campo do direito. Utilizando-se dos seus próprios instrumentos e expedientes legais, como as deliberações e decretos, o poder executivo se transformou no verdadeiro legislador do OP. Qualquer semelhança com o "poder soberano" da exceção (Agamben, 2004), infelizmente, não parece ser uma triste coincidência. Da mesma forma, Hannah Arendt (2000) já alertou que a exceção historicamente não ocorreu fora do aparato ou de um contexto de legalidade, mas, ao contrário, transformou-se na própria legalidade. É nessa "vereda" aberta ao pensamento que, inclusive, Oliveira (2003) analisa a cidade como expressão atual do "estado de exceção" na realidade brasileira.

As normas e referências legais da Lei Orgânica do município, do Estatuto da Cidade, da Lei Municipal 3.189 tornaram-se passíveis de subordinação aos atos de exceção do poder executivo - há muito transformados em norma e referência das formas de governar na sociedade. Basta, para tanto, recorrer à imagem da longevidade e importância das "medidas provisórias" de governo para se ter a noção do quanto a exceção pode ser de fato a norma.

E, como se não bastasse a imagem de um poder exercido dessa forma, há, ainda a preocupação de se fazer acompanhar de um discurso "democrático". Isso sim assustador, pois não se trata de uma cidade administrada por um "ditador", mas por um prefeito (e um projeto político de cidade e sociedade) que contou com a legitimidade institucional da vitória de três processos eleitorais quase ininterruptos. Eis a força e o embaralhamento profundo desse cenário político a desafiar a capacidade intelectual de interpretação.

Em termos legais, a gestão orçamentária participativa, no âmbito do planejamento municipal, é um dos instrumentos da política urbana definida pelo Estatuto da Cidade de 2001. Conforme previsto pelo referido marco legal, a gestão orçamentária participativa, "incluirá a realização de debates, audiências e consultas públicas sobre as propostas do plano plurianual, da lei de diretrizes orçamentárias e do orçamento anual, como condição obrigatória para sua aprovação pela Câmara Municipal." (CÂMARA MUNICIPAL DO RIO DE JANEIRO, 2002).

A Lei Orgânica do Município também define, em seu Artigo 255, a gestão democrática da cidade por meio da participação popular, enquanto a Lei Municipal 3.189, de 23 de março de 2001, regulamenta tal participação. Contudo, é o Regulamento do Orçamento Participativo que estabelece as normas e as regras da participação popular. Para tanto, deve ser elaborado e aprovado pelo Conselho Popular do Orçamento, discutido amplamente com a comunidade nos Fóruns Populares do Orçamento e revisado anualmente a partir das sugestões populares e do próprio conselho.

Desde 2002, a prefeitura está obrigada a se adequar a essas exigências. Nesse sentido, obedecendo a uma das suas obrigações legais, ${ }^{10}$ a prefeitura instituiu o Decreto 21.186, de 26 de março de 2002, que dispõe sobre o Regulamento Provisório do Orçamento Participativo. A partir desse regulamento foram criadas a Co-

\footnotetext{
${ }^{10}$ De acordo com o Artigo 26 da Lei Municipal 3.189/01 (Lei do Orçamento Participativo), "No primeiro ano [grifo nosso] do Orçamento Participativo, enquanto não estiverem constituídas as formas de organização de que trata esta Lei, caberá ao poder Executivo elaborar um regulamento provisório e assumir as tarefas indispensáveis ao seu funcionamento" (CÂMARA MUNICIPAL DO RIO DE JANEIRO, 2001).
} 
missão Executiva Provisória do Orçamento Participativo (CEPOP) e a Comissão Central Provisória do Orçamento Participativo (CCPOP).

Cabe descrever, de forma sintética, a dinâmica prevista legalmente para a gestão democrática da cidade por meio do orçamento participativo. Contudo, tal di-nâmica não se encontra implementada, até hoje, na cidade. Os elementos que se seguem demonstram, entretanto, a distância significativa entre o plano normativo e o factual das políticas de gestão urbana. As principais formas de organização do OP, previstas na Lei Municipal 3.189, são o Conselho Popular do Orçamento (CPO); a Comissão Central do Orçamento Participativo (CCOP) e os Fóruns Populares do Orçamento (FPO). Com composição e níveis de poder diferenciados, cada uma destas formas de organização prevê sempre uma eleição anual de seus membros durante as "rodadas de discussão". Há a clara orientação de ampliar os esforços e o poder de participação dos representantes da sociedade civil. Por isso, no CPO os doze membros de entidades da sociedade civil e os representantes das regiões ou setores de atividade pública (que representam as bases territorial e setorial do OP) possuem direito a voto, enquanto os membros do poder executivo no CPO, por exemplo, não possuem. Já a CCOP é composta de forma paritária entre os membros representantes do CPO e do poder executivo. Os FPO seguem a organização territorial e/ou setorial do OP e os representantes da comunidade são eleitos anualmente durante a primeira das duas rodadas de discussão do OP, em número proporcional ao de participantes na referida rodada de discussão. Cabe ao poder executivo, entre outras atribuições, fornecer as informações técnicas necessárias, implementar uma ampla campanha de divulgação nos diferentes veículos de informação local e oferecer as condições de infraestrutura necessárias às organizações da sociedade civil que atuarem na campanha, visando à informação e à convocação da população para o processo do OP.

A CEPOP, por meio da deliberação 001, de 10 de junho de 2002, instituiu as formas de participação da comunidade no OP de 2003 pautadas por uma metodologia fundamentada na dinâmica do II PECRJ. Os elementos mais importantes a serem destacados desta deliberação e da metodologia proposta são: 1) concentração das decisões na esfera do poder executivo que, além de integrar sozinho a CEPOP, possui a atribuição de análise das condições de viabilidade técnica e financeira das propostas e o poder de veto sobre elas e 2) subordinação da dinâmica democrática de publicização da gestão do orçamento da cidade ao espaço do Plano Estratégico e sua concepção de cidade e de desenvolvimento urbano.

Não há, no âmbito da Lei Municipal 3.189/01, a autorização para o poder Executivo reproduzir, nos anos subsequentes, a dinâmica adotada no primeiro ano do OP. Isso porque este ano é considerado período de implantação das formas de organização do OP. Uma vez implantadas, cabe a essas organizações o estabelecimento da dinâmica de cada processo anual de OP, desfazendo-se as ações anteriores do poder Executivo definidas, inclusive, sob a qualificação de "provisórias". Sendo assim, a não-realização do OP dos anos de 2004 em diante, sob a justificativa de serem "legítimas" as propostas dos planos estratégicos regionais, pois nasceram de um autodenominado processo de planejamento também pautado pela participação popular, é um exemplo claro do quanto os discursos da democracia e da 
participação podem ser usados para fins os mais diversos, inclusive os autoritários. E o mais fundamental: o quanto a democracia, esvaziada de seu conteúdo e forma política, transforma-se apenas na gestão eficiente e competitiva perseguida, há mais de uma década, pela Prefeitura do Rio de Janeiro por meio dos planos estratégicos I e II.

\section{Considerações Finais}

As análises até aqui formuladas a respeito da subordinação do OP ao II PECRJ não pretenderam estabelecer uma reflexão polarizada entre "OP autêntico" e o seu inverso. Nesse sentido, não se tratou de reivindicar um poder "acima de qualquer suspeita" à participação da sociedade civil e nem mesmo de que esta participação, caso se operasse fora do escopo do planejamento estratégico, fosse capaz de produzir resultados capazes de confrontar publicamente as atuais prioridades e critérios de aplicação do orçamento nos destinos da cidade. Penso que a contribuição principal do texto está no esforço de investigação empreendido para realçar a forma como as políticas de empreendedorismo urbano operam a partir da desnecessidade da política, ao mesmo tempo que a ritualizam em um conjunto de procedimentos, técnicas, documentos, cifras, indicadores e propostas que possuem a capacidade de se apropriar de vários elementos institucionais da democracia participativa para, então, esvaziá-la inteiramente de seu sentido.

Ao mesmo tempo, e este sim parece ser um registro teórico e político importante, todo esse processo de planejamento da cidade ocorreu sem a explicitação de qualquer forma de "litígio" entre o Estado e as formas de representação política dos trabalhadores, como, por exemplo, os sindicatos. O Fórum Popular do Orçamento tem sido um sujeito político coletivo importante nesse campo de luta e, de forma mais geral, no campo dos conflitos urbanos do planejamento estratégico.

A partir da problematização das práticas de planejamento urbanos estudadas e da articulação dessas à agenda de "boa governança" do BIRD, pode-se concluir que o direito à cidade só se manifesta como realidade possível por meio do direito a ter direito (ARENDT, 2000) a essa reivindicação pública. Portanto, é por meio do fortalecimento da política, como forma de partilha do mundo comum e forma de nomear e atribuir pertinência e significado às relações e objetos desse mundo, que o direito à cidade se faz como obra humana (LEFEBVRE, 2001). É a mediação da política que faz a passagem das diversas formas de expressão do direito à cidade e de sua negação, à condição de assuntos pertinentes ao debate público e portadores do conflito entre as classes.

Assim, o que se buscou evidenciar com a subordinação dessa prática de inspiração democrática à lógica e à dinâmica de funcionamento do II PECRJ foi a anulação da política ou, nos termos de Hannah Arendt (1999), a anulação da pluralidade necessária à sustentação da condição humana do próprio mundo como fenômeno político. E essa pluralidade, necessária à sustentação da palavra e da ação, não ocorre fora de um campo de aparência/visibilidade - ou seja, fora de uma esfera pública. Os rituais de participação que se estabelecem para a produção do "mesmo", de homogeneidades, de opiniões indistintas não possibilitam mais do que a agregação física. No sentido Arendtiano (1999), são esvaziados de "poder". 


\section{Referências Bibliográficas:}

AGAMBEN, Giorgio. Estado de exceção. São Paulo: Boitempo, 2004.

ARENDT, Hannah. A condição humana. Rio de Janeiro: Forense Universitária, 1999. . As origens do totalitarismo. São Paulo: Cia. das Letras, 2000.

ARANTES, Pedro. $O$ ajuste urbano: as políticas do Banco Mundial e do BIRD para as cidades latino-americanas. São Paulo. Dissertação de Mestrado em Estruturas Ambientais Urbanas. Faculdade de Arquitetura e Urbanismo da Universidade de São Paulo, 2004. mimeo.

BANCO MUNDIAL. Ciudades en transición. Resumen estratégia del banco mundial para los gobiernos. Grupo de Infraestrutura Desarrolo Urbano. Washington: Banco Mundial, 2000.

. Estratégia de assistência ao país do Grupo Banco Mundial para a República Federativa do Brasil, 12 de junho. 1997. In: VIANA JUNIOR, Aurélio (org.). A estratégia dos bancos multilaterais para o Brasil. Análise crítica e documentos inéditos. Brasília: Rede Brasil, 1998.

. Rio de Janeiro: um estudo da cidade (Parte I).19 de junho. 1999. PREFEITURA DA CIDADE DO RIO DE JANEIRO - Rio Estudos. Rio de Janeiro: Secretaria Municipal de Urbanismo/Instituto Pereira Passos, n. 32, setembro. 2001 (Coleção Estudos da Cidade).

. Rio de Janeiro: um estudo da Cidade (Parte II). 19 de junho. 1999a. PREFEITURA DA CIDADE DO RIO DE JANEIRO - Rio Estudos. Rio de Janeiro: Secretaria Municipal de Urbanismo/Instituto Pereira Passos, n. 33, setembro. 2001 (Coleção Estudos da Cidade).

. Desenvo/vimento econômico local: um manual para a implantação de estratégias para o desenvolvimento econômico local e planos de ação. Washington, DC: Banco Mundial (BIRD), 2006.

BARROS, Flávia (org.). As estratégias dos bancos multilaterais para o Brasil. Brasília: Rede Brasil, 2001.

BRITO, Ana Lúcia e PORTO, Hélio R. Serviço de saneamento na Baixada Fluminense: problemas e perspectivas. Rio de Janeiro: IPPUR/FASE, 1998.

CÂMARA MUNICIPAL DO RIO DE JANEIRO. Lei 3.181, 23 de março. 2001. Dispõe sobre a participação da comunidade no processo de elaboração, definição e acompanhamento da execução do Orçamento Plurianual de Investimentos, das Diretrizes Orçamentárias e do Orçamento Anual. Rio de Janeiro: Câmara Municipal do Rio de Janeiro, março. 2001. Disponível em http://cmrj1.cmrj. gov.br/Apl/Legislativos/leis.nsf. Acesso em 20 de julho. 2003.

. Lei Orgânica do Município do Rio de Janeiro: Rio de Janeiro. Câmara Municipal do Rio de Janeiro, setembro. 2004. Disponível em http://www2.rio.rj. gov.br/pgm/leiorganica/leiorganica.html\#t5c3. Acesso em 30 de junho. 2006. CARDOSO, Isabel Cristina C. Cenas cariocas de transformação nas formas urbanas da cidade e do trabalho. Onde está a invenção política? São Paulo: Tese de doutorado em Sociologia, Faculdade de Filosofia Letras e Ciências Humanas da Universidade de São Paulo, 2005.

CASTELLS, Manuel e BORJA, Jordi. As cidades como atores políticos. Novos Estudos, n. 45, São Paulo: CEBRAP, julho 1996. pp. 153-66. 
COMPANS, Rose. Empreendedorismo urbano: entre o dicurso e a prática. São Paulo: Editora UNESP, 2005.

FERREIRA, João Sette Whitaker. O mito da cidade-global. O papel da ideologia na produção do espaço urbano. Petrópolis: Vozes; São Paulo: Editora UNESP; Salvador: ANPUR, 2007.

HARVEY, David. A produção capitalista do espaço. São Paulo: AnnaBlume, 2005. LEFEBVRE, Henri. O direito à cidade. 2 ed. São Paulo: Centauro, 2001. LESSA, Carlos. O Rio de todos os Brasis. Uma reflexão em busca da autoestima. 2 ed. Rio de Janeiro: Record, 2001.

MOREIRA BRAGA, Tânia. Desenvolvimento local endógeno: entre a competitividade e a cidadania. Revista Brasileira de Estudos Urbanos e Regionais, n. 5. Rio de Janeiro: Associação Nacional de Pós-Graduação e Pesquisa em Planejamento Urbano e Regional, 2001, pp. 25-40.

OLIVEIRA, Francisco de. O Estado e a exceção: ou o Estado de exceção? Revista Brasileira de Estudos Urbanos e Regionais, v. 5, n. 1. Rio de Janeiro: Associação Nacional de Pós-Graduação e Pesquisa em Planejamento Urbano e Regional, 2003, pp. 9-14.

PREFEITURA DA CIDADE DO RIO DE JANEIRO. Plano estratégico da cidade do Rio de Janeiro "Rio sempre Rio". Rio de Janeiro, 1996.

- Orçamento participativo do município do Rio de Janeiro. Exercício de 2003. Rio Estudos. Rio de Janeiro: Secretaria Municipal de Urbanismo/Instituto Pereira Passos, n. 74, outubro. 2002 (Coleção Estudos da Cidade). - Programa de desenvolvimento para a Cidade do Rio de Janeiro. Rio Estudos. Rio de Janeiro: Secretaria MuniScipal de Urbanismo/Instituto Pereira Passos, n. 11, julho. 2003 (Coleção Estudos da Cidade).

Segundo Plano estratégico da cidade do Rio de Janeiro: as cidades da cidade. Rio de Janeiro, 2002. Disponível em http://www.rio.rj.gov.br/plano estrategico/. Acesso em 20 de março. 2004.

. Cidade apresenta maior capacidade de investimento no Brasil. Rio

Estudos Especial. Rio de Janeiro: Secretaria Municipal de Urbanismo/Instituto Pereira Passos, janeiro. 2005 (Coleção Estudos da Cidade).

RANCIÈRE, Jacques. O desentendimento: política e filosofia. São Paulo: Ed. 34, 1996.

SANTOS, Milton. A natureza do espaço. São Paulo: EDUSP, 2004.

VAINER, Carlos B. Pátria, empresa e mercadoria. Notas sobre a estratégia do planejamento estratégico urbano. In: ARANTES, Otilia; VAINER, Carlos e MARICATO, Ermíria (orgs.). A cidade do pensamento único: desmanchando consensos. 2 ed. Petrópolis: Editora Vozes, 2000.

Recebido em 03 de agosto de 2009.

Aceito para publicação, em 10 de outubro de 2009. 